Thomson, J. (1887). F. R, anthrop. Inst. x6, I82.

Vavilov, N. I. (1931). Address to the 2nd International Congress on History of Science and Technology.

Walters, J. H. \& Smith, D. A. (1952). W. Afr. med. F. (N.S.) I, 2 I.

World Health Organization: Expert Committee on Alcohol (1954). Tech. Rep. Wld Hlth Org. no. 84.

\title{
Alcohol in Intravenous Feeding
}

\section{By A. W. Wilkinson, Surgery Department, University of Aberdeen}

Some degree of starvation is a common and accepted sequel to severe injury, and for several days after major operations patients usually lose their appetite and do not eat. In the past attempts have been made to avoid this period of starvation by means of intravenous feeding with protein hydrolysates and various sources of energy. Close examination of the normal response to injury shows, however, that the well-nourished patient has an inherent capacity to survive injury and starvation and to heal his wounds, that after injury the organism so orders its economy that it provides from its own substance the raw materials for the repair of injured tissues as well as the daily energy requirements. The present tendency is thus once more to leave the body as much as possible to its own rather inscrutable devices during the postoperative period. This attitude means that the potential field for intravenous feeding, including the administration of alcohol, has again contracted to the few states in which a patient is unable to ingest or digest food by the alimentary tract.

The value of parenteral nutrition is rather uncertain but there may be some place for it in the treatment of patients with fistulas of the small intestine, ulcerative colitis, advanced malnutrition and some forms of hepatic disease. Originally a 5 or $6 \%$ solution of amino-acids derived from the acid or enzymic hydrolysis of milk protein was combined with a source of energy such as glucose. The success of intravenous feeding with protein depends, however, on the provision of an adequate accompaniment of calories, which has given rise to most practical difficulties.

An uninjured healthy person lying in bed probably requires about $2100 \mathrm{Cal} /$ /day, but this basal requirement is increased after injury and by other forms of inflammation (Cuthbertson, 1945). To supply $2100 \mathrm{Cal}$. would entail the daily infusion of over II 1 . of $5 \%$, or 5.61 . of $10 \%$, glucose solution. Even normal subjects have only a limited tolerance for repeated large intravenous infusions; after injury and in inflammation of all kinds this tolerance is greatly reduced and, apart from the replacement of losses of body fluids, not more than $2.5 \mathrm{l}$./day can be safely administered. Emulsions containing up to $30 \%$ of fat have been developed and administered intravenously and are safe and satisfactory sources of calories but have a limited stability or 'shelf-life'. A I $5 \%$ fat emulsion would provide 1200 Cal./l. but, unfortunately, is still not commercially available. These various difficulties in providing adequate supplies of energy to accompany or 'cover' infusions of protein 
hydrolysates have led to consideration of the use of alcohol as an alternative source of calories.

The first intravenous infusion of alcohol appears to have been given at Oxford in 1657,29 years after the publication by Harvey (1628) of De Motu Cordis. At the instigation of the Professor of Astronomy, Christopher Wren, the Hon. Dr Robert Boyle injected warmed sack containing opium into the vein of a hind limb of a large dog.

Atwater \& Benedict (1902) showed that alcohol could replace fat and carbohydrate in the diet and could probably exert a sparing effect on protein metabolism. Mellanby (I9I9) found that alcohol simply replaced other foodstuffs without increasing the total energy expenditure, and that its rate of oxidation was independent of the other types of foodstuffs being metabolized; he concluded that about $8.0 \mathrm{~g}$ or Io $\mathrm{ml}$. of alcohol could be metabolized per hour, a figure rather higher than the results obtained later by Widmark ( 1933 ) of $7 \cdot 3 \mathrm{~g}$ for men and $5 \cdot 3 \mathrm{~g}$ for women.

After a single drink of alcohol, the blood concentration rises rapidly to a peak and then declines steadily in a linear fashion (Mellanby, 1919). Since only about $3 \%$ of the dose of alcohol is excreted in the urine and expired air, the change in blood concentration can be used to measure the rate of oxidation of the alcohol; this rate has been found to vary with the dosage and from one person to another. With intravenous infusions of alcohol at a constant rate Eggleton (r940a,b) showed that there was a rather slow increase of blood-alcohol concentration until a steady level was reached which varied with the dose. Eggleton also found that equilibrium was established within $30 \mathrm{~min}$ between plasma and muscle, and throughout the body after about an hour. At equilibrium the concentration of alcohol in most tissues in the body is $70-80 \%$ of that in the plasma, but fat contains only 10-20\% of the plasma concentration. Smith \& Stewart (1932) found that the alcohol content of bone also is low. Thus most of the alcohol is distributed in the non-fatty tissues of the body or the 'lean tissue mass', which rather suggests that the volume of distribution of alcohol in the body approaches that of the body water, which in a lean adult male is about $60 \%$ of the ideal body-weight.

In several countries it has been accepted as a reasonable legal procedure to calculate the body content, and hence the consumption or dose of alcohol, from the observed blood concentration. During the continuous intravenous infusion of alcohol at a steady rate the blood concentration remains low so long as the rate of injection does not greatly exceed the rate of oxidation. Although oxidation proceeds more rapidly as the plasma concentration of alcohol rises, even at low concentrations a fairly high rate of oxidation can be achieved, and the importance of this in clinical work is obvious.

Fig. I shows what happened when $\mathrm{r} \cdot 51$. of a solution containing $6 \%$ ethyl alcohol and $5 \%$ amino-acids was injected into a convalescent male, aged 30 years and weighing $64 \mathrm{~kg}$. The infusion lasted $5 \mathrm{~h}$ and was at nearly three times the rate I have usually employed. Line $a$ shows the rate of injection in $\mathrm{ml}$. alcohol $/ \mathrm{h}$ and the cumulative total. If this dose were metabolized at $10 \mathrm{ml} . / \mathrm{h}$, a rate indicated by line $b$, the difference between these two lines would indicate the unoxidized alcohol 
remaining in the body at any time. If this remainder were distributed through this man's body water, the alcohol would reach a concentration in the plasma shown by line $d$. Blood was withdrawn every hour and the blood-alcohol concentration was estimated by the Cavett method (Kent-Jones \& Taylor, 1954). These observed concentrations (line $e$ ) were only about half those predicted (line $d$ ).
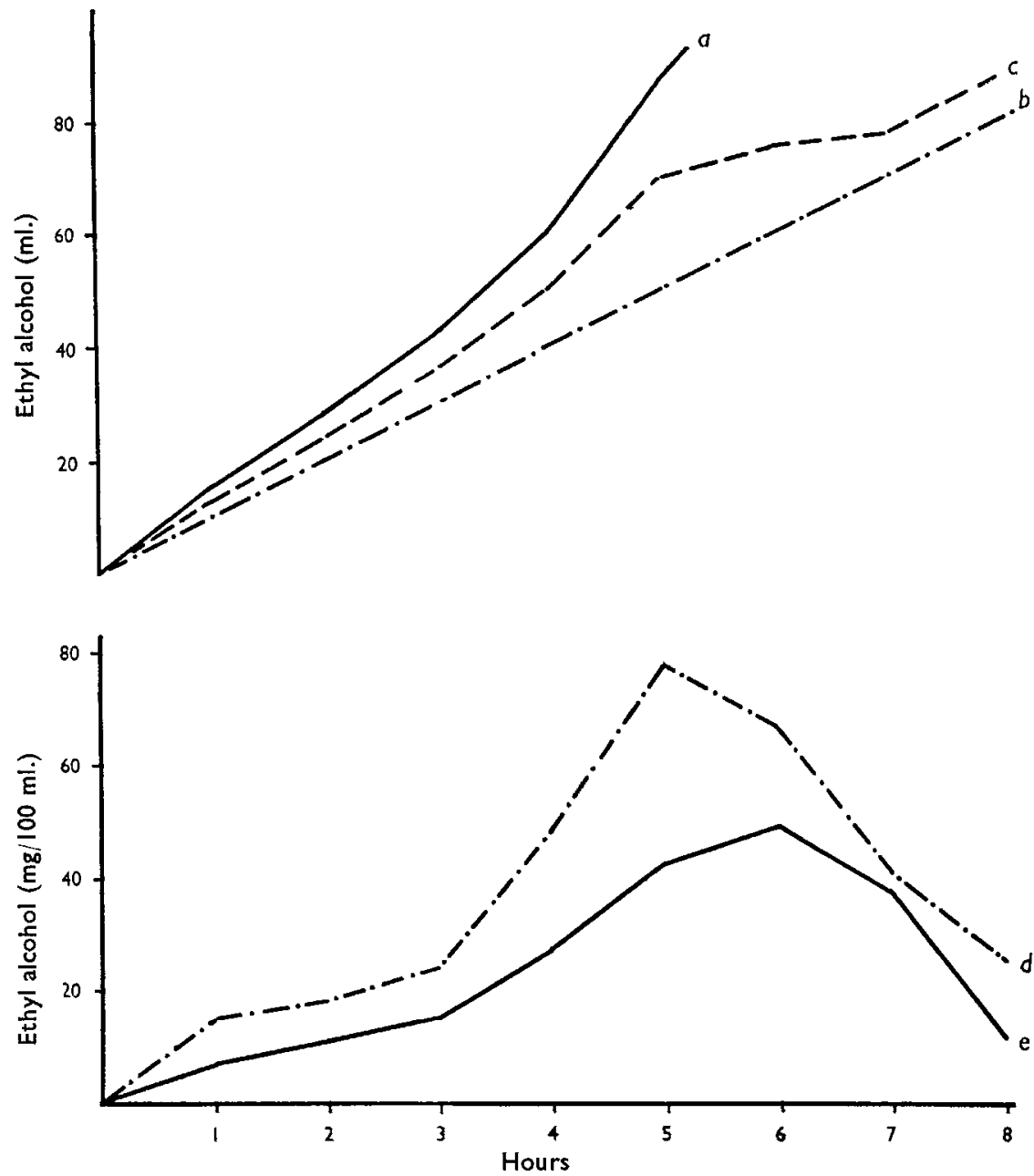

Fig. I. Effect of injecting intravenously a solution containing $6 \%$ ethyl alcohol and $5 \%$ amino-acids into a convalescent man aged 30 years and weighing $64 \mathrm{~kg}$. $a$, rate of injection of alcohol; $b$, rate of oxidation of alcohol (ro $\mathrm{ml} . / \mathrm{h}$ ); $c$, corrected rate of oxidation of alcohol; $d$, predicted values for plasma-alcohol concentration; $e$, measured values for blood-alcohol concentration.

Part of this difference is due to the plasma concentration being $10-20 \%$ higher than the blood concentration at equilibrium (Eggleton, 1940a,b). The remainder may be due to the rate of oxidation having exceeded to $\mathrm{ml} . / \mathrm{h}$. From the observed bloodalcohol concentration it has been calculated that oxidation (line $c$ ) was at the rate of $12.5 \mathrm{ml} . / \mathrm{h}$ when the injection rate was $15 \mathrm{ml} / \mathrm{h}$, and $\mathrm{I} 4 \mathrm{ml} . / \mathrm{h}$ when the injection 
rate was increased to $17 \mathrm{ml} / \mathrm{h}$. The rate of oxidation fell when the infusion was stopped.

During a continuous infusion when the rate of oxidation equals the rate of administration a steady plasma concentration is maintained. In order to estimate an appropriate dose Rice, Orr \& Enquist (1950) calculated or measured the caloric consumption of their patients and administered alcohol at a rate that would provide twice the total caloric requirements of the individual. They found that the bloodalcohol concentration rose rapidly during the ist hour of the infusion and then became stable. If they then reduced the rate to about one and a half times the caloric requirements the blood concentration remained at about $80 \mathrm{mg} / \mathrm{roo} \mathrm{ml}$. This higher concentration was due to the rapid initial rate of infusion which exceeded two or three times the rate of oxidation. After thus slowing the infusion they usually gave I 1 . of solution containing $60 \mathrm{ml}$. of alcohol over a period of $4 \mathrm{~h}$. During a similar period I have usually administered only $500 \mathrm{ml}$. of solution containing $6 \%$ alcohol, but even at this slower rate it is still possible to administer in $24 \mathrm{~h}$ a total of $3 \mathrm{l}$. containing $\mathrm{I} 8 \mathrm{o} \mathrm{ml}$. alcohol, equivalent to about a pint of whisky.

In Table I several solutions for intravenous infusion are compared. In solution $A$ the total provision of calories/l. fluid infused is low and the proportion derived from the amino-acids is excessive. In solution $B$ the total and the non-protein fraction of calories have been increased by substituting alcohol for glucose. The advantages of combining alcohol and glucose are shown in solutions $C$ and $D$,

\section{Table $\mathrm{x}$. Comparison of solutions used for intravenous feeding}

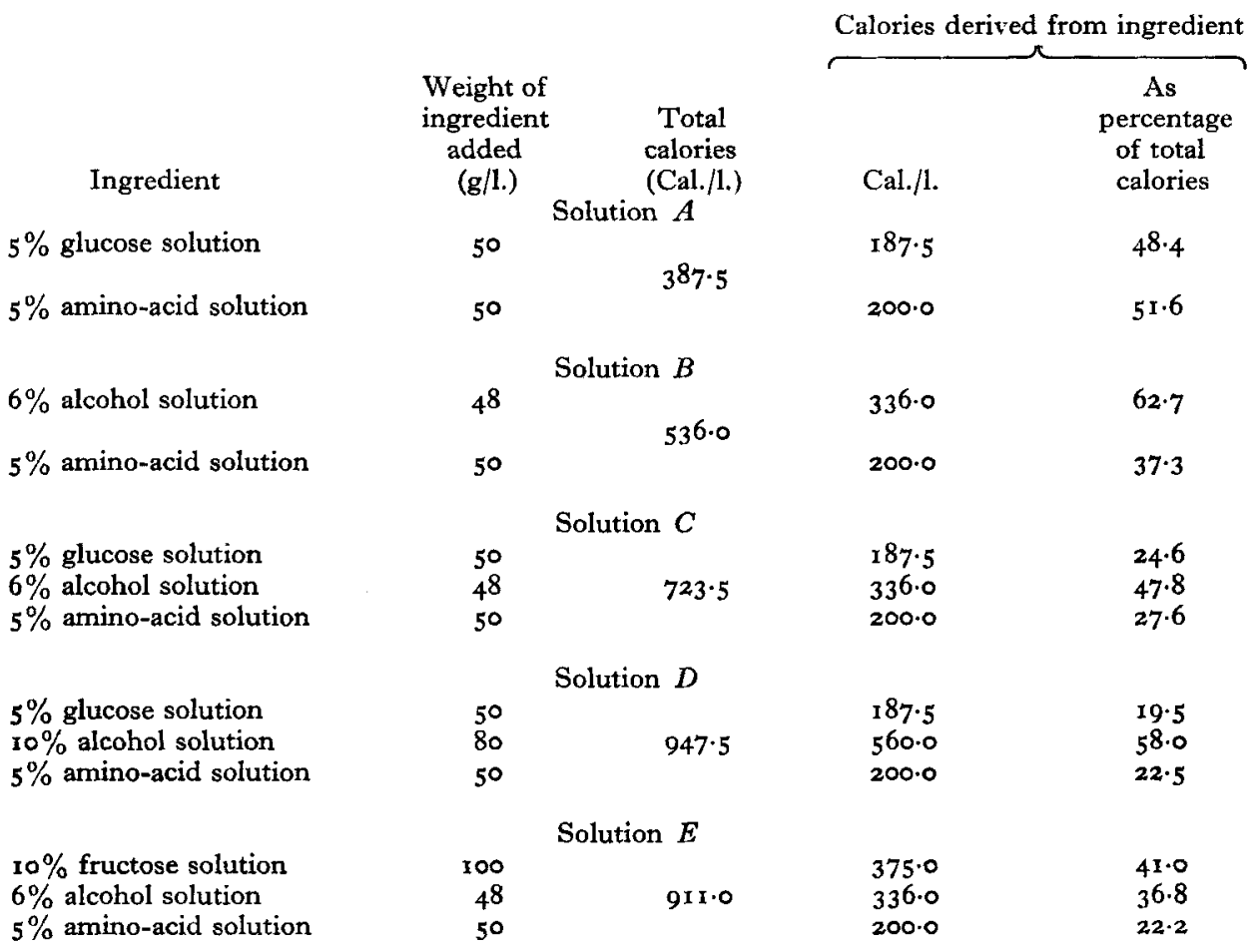


but the proportion of calories from alcohol in solution $D$ is undesirably high. When a glucose solution is administered by intravenous infusion the proportion of the glucose lost in the urine varies with the concentration used and the rate of infusion and may be as high as $30 \%$. This glycosuria is less marked during and after infusions of invert sugar than with glucose (Lawton, Curreri \& Gale, r95 I), and this advantage is rather greater with fructose than with invert sugar (Weinstein $\&$ Roe, 1952). The urinary wastage of both amino-acids and polypeptides is reduced when fructose is used instead of glucose in combination with protein hydrolysates (Christensen, Wilber, Coyne \& Fisher, I954); the more frequent achievement of nitrogen balance with this combination has been ascribed to the more rapid removal of fructose from the blood stream. Especially when used at a concentration of $10 \%$ both invert sugar and fructose thus have advantages over glucose. A further advantage of fructose may depend on its effect on the metabolism of alcohol; MartensenLarsen (1954) has recently drawn attention to the apparent increase of $20-90 \%$ in the rate of oxidation of alcohol following the oral administration to drunk people of fructose, either pure or as Danish honey. In solution $E$ (Table I) the substitution of $10 \%$ fructose for $5 \%$ glucose increases the non-protein calories to nearly $80 \%$ of the total, with alcohol providing only $36.8 \%$ as compared with $58 \%$ in solution $D$.

There is no doubt that solutions containing alcohol can be safely administered by intravenous infusion. Mueller (1939) reported 2000 infusions of 5 or $10 \%$ alcohol in saline or glucose saline, and gave from 100 to $150 \mathrm{ml}$. alcohol/day. During 3 weeks a diabetic with a high intestinal fistula was given $521.5 \%$ glucose and $5 \%$ alcohol and another patient with plastic peritonitis was given 451 . Rice, Strickler \& Erwin (1952) administered over 5001 . of a solution of $5 \%$ alcohol, $5 \%$ aminoacids and $12 \%$ invert sugar to 109 patients without ill effects. In one of these patients the infusion was continued for 42 days. I have administered about 601 . of $6 \%$ alcohol and 201 . of $10 \%$ alcohol with amino-acids. One patient, with a small intestinal fistula secondary to.a plastic peritonitis, received 25 l. over 13 days.

Chemical thrombophlebitis is a common complication of the prolonged intravenous infusion of glucose solution and is due to its low $\mathrm{pH}$. The incidence of phlebitis was not affected by the addition of alcohol to the fluid, but the discomfort in the affected vein was increased and there was more redness of the overlying skin. Haemolysis was not encountered although it is said to be common when ethyl alcohol is injected into experimental animals and occurred in over $30 \%$ of Mueller's (r939) infusions.

During an infusion the skin usually became flushed and warm; this flushing is probably due to the amino-acids since it usually accompanies infusions of aminoacids without alcohol, and the blood-alcohol concentration was probably too low for alcohol to be the cause. A few patients complained of headache but most commonly slept quietly. Signs of intoxication did not appear, the patients were not noisy or obstreperous and none vomited or was nauseated. The urinary output increased during and after the infusion and the volume of urine was about equal to the volume of the infused fluid. The administration of $100 \mathrm{ml}$. solution $/ \mathrm{h}$ corresponds to a 
dosage of 6 or io $\mathrm{ml}$. alcohol $/ \mathrm{h}$, according to the strength of the solution, the oxidation of which was well within the metabolic capacity of any patient who has been treated. When $100 \mathrm{ml}$. saline or some other fluid is run in between each $500 \mathrm{ml}$. of solution containing alcohol, this short interval further reduces any tendency for the blood-alcohol concentration to rise steadily. That this may be worth while is shown by the report of Moore \& Karp (1945) who found that some of their patients became inebriated when the infusion was too rapid.

Alcohol infusions have been used in widely different circumstances. A large number of infusions have been reported to have been employed in vain attempts to maintain positive nitrogen balance during the immediate postoperative period, and in many of these the low non-protein fraction of the total calories made failure inevitable. Infusions have also been given without apparent advantage simply to supply calories during the first day or two after operation.

I reserved alcohol infusions mainly for patients who were in advanced states of malnutrition and who could not be fed by mouth or jejunostomy. For example, in order to provide supplementary protein and calories four patients with hepatic disease and jaundice who were so nauseated as to be unable to consume food received up to 21 . of $6 \%$ alcohol and amino-acids daily for 4 or 5 days. Some benefit seems to be derived in the initial stages of treatment by a few patients with advanced malnutrition but direct evidence of nutritional improvement has not been obtained. Alcohol should not be administered intravenously to patients with recent head injuries or with intracranial disease and should not be used in coma associated with raised intracranial pressure. A few prolonged infusions have been maintained in attempts to feed seriously ill patients entirely by the intravenous route; these were all rather hopeless enterprises, but seem worth while and are occasionally successful. Better results may be obtained in the future by the combination of $10 \%$ fructose with alcohol and amino-acids.

I am indebted to $\mathrm{Mr} \mathrm{L}$. E. Martin for measurements of the blood-alcohol concentration and to Benger's Laboratories Ltd for providing the amino-acid (Casydrol) and alcohol preparations which have been used.

\section{REFERENCES}

Atwater, W. O. \& Benedict, F. G. (1902). Mem. nat. Acad. Sci. 8, 23 r.

Christensen, H. N., Wilber, P. B., Coyne, B. A. \& Fisher, H. (I954). F. clin. Invest. 33, 923.

Cuthbertson, D. P. (1945). Brit. med. Bull. 3, 96.

Eggleton, M. G. (1940a). F. Physiol. 98, 228.

Eggleton, M. G. (1940b) f. Physiol. 98, 239.

Harvey, W. (1628). De Motu Cordis et Sanguinis in Animalibus. Francofurti: Tuilielmus Sitzerus.

Kent-Jones, D. W. \& Taylor, G. (1954). Analyst, 79, I21.

Lawton, B. R., Curreri, A. R. \& Gale, J. W. (195I). Arch. Surg. 63, 561.

Martensen-Larsen, O. (1954). Brit. med. $F$. ii, 464 .

Mellanby, E. (1919). Spec. Rep. Ser. med. Res. Coun., Lond., no. 31.

Moore, D. C. \& Karp, M. (1945). Surg. Gynec. Obstet. 80, 523.

Mueller, S. (1939). Surg. Clin. N. Amer. 19, 40 I.

Rice, C. O., Orr, B. \& Enquist, I. (1950). Ann. Surg. 131, 289.

Rice, C. O., Strickler, J. H. \& Erwin, P. D. (1952). Arch. Surg. 64, 20.

Smith, S. \& Stewart, C. P. (1932). Brit. med. J. i, 87.

Weinstein, J. J. \& Roe, J. H. (1952). F. Lab. clin. Med. 40, 39.

Widmark, E. M. P. (1933). Biochem. F. 267, 128. 